City University of New York (CUNY) CUNY Academic Works

1997

\title{
La historificación de la lingüística histórica: los "Orígenes" de Ramón Menéndez Pidal
}

José del Valle

CUNY Graduate Center

\section{How does access to this work benefit you? Let us know!}

More information about this work at: https://academicworks.cuny.edu/gc_pubs/76

Discover additional works at: https://academicworks.cuny.edu

This work is made publicly available by the City University of New York (CUNY).

Contact: AcademicWorks@cuny.edu 
Historiographia Linguistica XXIV:1/2.175-196 (1997). @ John Benjamins B.V., Amsterdam Not to be reproduced in any form without written permission from the publisher.

\title{
LA HISTORIFICACIÓN DE LA LINGǗ́STICA HISTÓRICA
}

\author{
LOS ORfGENES DE RAMÓN MENÉNDEZ PIDAL*
}

\author{
JOSÉ DEL VALLE \\ Miami University, Ohio
}

"When you read a work of history, always listen out for the buzzing. If you can detect none, either you are tone deaf or your historian is a dull dog."

Edward H. Carr (1961)

\section{Introducción}

La ciencia de la historia de orientación positivista - que Edward H. Carr ha denominado "the empirical or common-sense school of history" (1961:7) - parte de una posición epistemológica que concibe al sujeto que observa y al objeto observado como entidades independientes, de modo que la historia queda reducida a una secuencia cronológica de hechos verificables, y su estudio a la fiel reproducción de estos hechos.

El desprestigio en el que en la actualidad ha caído esta escuela de pensamiento histórico (bajo el impulso de la teoría cultural de corte bajtiniano y de la filosofía posestructuralista, entre otras) se debe fundamentalmente al reconocimiento de que tanto el historiador como el hecho historificado son producto de la historia, es decir, existen y operan en circunstancias específicas que determinan su naturaleza y su operatividad. Sabemos hoy que la posición social e intelectual del observador condiciona la selección de hechos históricos (que reciben trato prominente frente a otros no merecedores de tal consideración), y determina las categorías que éste aplica al ordenamiento intelectual de aquellos hechos. La ciencia de la historia debe, por lo tanto, reconocerse a sí misma como un diálogo entre el pasado, el presente y el futuro, y su objetivi-

\footnotetext{
* No puedo dejar de reconocer mi deuda con Michael Gerli por guiar mis primeros pasos por estos asuntos, y con mi colega y amigo Raúl Ianes por hacerme ver que "así se escribe la historia". Agradezco también a Juan C. Zamora Munné el haberme mvitado a participar en el Coloquio internacional de historia de la lingülstica en España e Hispanoamérica obligándome así a ordenar por fin algunas de mis notas.
} 
dad (valor relativo) depende no tanto del rigor factual del estudio (que, como afirma Carr, es obligación más que virtud del historiador), sino de la relevancia de un hecho en relación con el objetivo general que el historiador se impone (y que, obviamente, responde a inquietudes del presente y del futuro).

El marco teórico que inspira este trabajo, es la teoría de la emergencia propuesta por Laurendeau (1990). Para este autor, la lingüística, como toda disciplina científica, no es ideológicamente neutral, sino que surge y existe como producto de una tensión entre el desarrollo del conocimiento práctico que proporciona y los elementos ideológicos que en ella influyen. Laurendeau propone la historificación de la lingüística, situándose así entre dos corrientes historiográficas dominantes: la historiografía propiamente dicha y el historicismo. Aquella tiende a la "enumeración cronológica de acontecimientos intelectuales"1 y, ya sea implícita o explícitamente, confiere al hecho histórico una existencia autónoma con respecto al actor social. Por su parte, el historicismo, tiende a localizar "todo acontecimiento intelectual en relación directa con lo que podríamos llamar su contexto histórico-anecdótico", 2 de modo que se presupone o se da a entender que el actor social tiene control absoluto sobre la producción intelectual. Pues bien, frente a ambas, Laurendeau propone la teoría de la emergencia, que "ve en toda escuela de lingüística un producto indirecto y relativamente autónomo de contextos socio-históricos concretos, y trata de describir la emergencia de una escuela linguística invirtiendo el orden de su desarrollo, es decir, partiendo de los resultados establecidos y yendo hacia sus fuentes teóricas y materiales" ${ }^{3} \mathrm{El}$ atractivo de esta teoría reside en que acepta que la evolución de una disciplina responde tanto a la dinámica interna de la misma como a los contextos ideológicos en los cuales se desenvuelve.

Ni que decir tiene que señalar las fuentes científicas e ideológicas de una idea o cuerpo de ideas no significa rechazarla. Debe quedar claro que al identificar en una escuela lingüística la tensión entre ciencia e ideología (lo que Laurendeau llama critique) y las manifestaciones en los textos por esa escuela producidos de la realidad socio-histórica (lo que Laurendeau llama hermeneutics) 1 "TT]he chronological enumeration of intellectual events as if they had a sort of independence
from any historicity" (Laurendeau 1990:208).

2 " [A] reaction to the first attitude that puts every intellectual event in direct relation with what could be called its 'anecdotal-historical' context" (Laurendeau 1990:208).

3 "This theory sees in every school of linguistics an indirect and 1990:208). duct of concrete socio-historical contexts, and tries to describe the emergence of a linguistic school, proceeding backwards from its established results towards the complete mix of its theoretical and material sources" (Laurendeau 1990:212). no se está necesariamente emitiendo juicios sobre su valor, veracidad o falsedad.

En líneas generales, éste es el aparato conceptual con el cual, a lo largo del presente artículo, pretendo aproximarme a los orígenes de la lingüística histórica moderna en España. En las próximas páginas, me propongo por lo tanto reivindicar la necesidad de historificar la lingüística histórica española y apuntar en una dirección que conduzca a tal meta.

\section{Contextos}

En cualquier visión panorámica de la historia intelectual de España en el último siglo se destaca la gigante figura de don Ramón Menéndez Pidal (18691968). Su importancia viene dada, en primer lugar, por la producción de múltiples obras consideradas clásicos de la filología española, entre las cuales se encuentran la edición y gramática del Poema del Cid̈, piedra angular de la épica española; el Manual de gramática histórica española y Orígenes del español, textos ambos que han informado y siguen informando a generaciones de estudiantes de humanidades en España; o Los españoles en la historia, pequeña obra de carácter divulgativo y de amplia difusión que cala en el origen y ser de la civilización española. Pese a disponer de una personalidad que sus biógrafos (y él mismo) califican de sobria e introvertida, tuvo Pidal el rigor, la presencia de ánimo y el temple necesarios para desempeñar el papel de liderazgo que sus tiempos le encomendaron. Desde la cátedra de filología comparada del latín y el castellano (a la que accedió en 1899), desde la Junta para la Ampliación de Estudios (en la que ingresó en 1907), desde el Centro de Estudios Históricos (que dirigió entre 1910 y 1936), desde la Real Academia Española (en la que ingresó en 1902 y que dirigió a partir de 1926, con una interrupción de 10 años durante y después de la Guerra Civil), o desde la Academia de la Historia (a la que se sumó en 1916), don Ramón Menéndez Pidal, además de desarrollar una obra de dimensiones grandiosas, generó un diálogo elevado y paciente con sus contemporáneos, inspiró y formó a los grandes intelectuales de la España del siglo veinte; sentó las bases, en definitiva, para el desarrollo de una escuela de pensamiento que habría de forjar con una fidelidad más o menos ortodoxa la concepción moderna de España.

Menéndez Pidal vivió un siglo de la historia de su país en el que se sucedieron períodos de calma y turbulencia social, momentos de gloria intelectual y desastre político, explosiones de libertad y feroz represión. Panorama a la vez abrumador e inspirador para un intelectual como don Ramón: tímido,

${ }^{4}$ Libro cuya primera edición, la de 1904, recibio el título de Manual elemental de gramática histórica española. 
sensible, trabajador y superlativamente intuitivo. Nació (casi) con la Gloriosa (la Revolucion de Septiembre de 1868). Durante su infancia se sucedieron la Primera República, la Restauración, las revueltas cantonalistas, la Segunda Guerra Carlista, pronunciamientos varios y la inauguración del 'Turno Pacífico' entre los liberales de Sagasta y los liberalconservadores de Cánovas del Castillo. Ya en su madurez, viviría acontecimientos tan intensos como la derrota militar de España ante Estados Unidos, la pérdida de los últimos reductos coloniales, el fortalecimiento político de los movimientos regionalistas en Cataluña, País Vasco y Galicia; la dictadura de Primo de Rivera; la Segunda República y la Guerra Civil (que lo llev6́ a un breve pero doloroso exilio).

El siglo diecinueve español, tras la inyección de patriotismo que había supuesto la derrota infligida a Francia en 1814, fue testigo de una constante desavenencia entre los sectores de población que habían adoptado los ideales del liberalismo y los poderes del antiguo régimen. En este contexto político, avanzaba con lentitud y de un modo desigual una revolución industrial a la que, según Pierre Vilar (1985:73-75), el progreso económico y demográfico del dieciocho parecían haber augurado un desarrollo más feliz. Privilegios locales heredados del antiguo régimen, desarrollo económico dispar de las regiones de España y la irrupción en la cultura europea del concepto de nación-estado, ponen en tela de juicio la unidad forjada por la monarquía borbónica durante el siglo dieciocho, que empieza a resquebrajarse al llegar la onda expansiva del nacionalismo a Cataluña, Galicia y País Vasco. La articulación de España como unidad política, económica y cultural fue un objetivo prioritario del liberalismo decimonónico y se manifestó tan pronto como se redactó la Constitución de Cádiz de 1812.5 Sin embargo, a lo largo del siglo van surgiendo trabas a la unificación, pues al secesionismo de la España ultramarina lo sucede el fantasma del secesionismo de la España periférica. El carlismo, por ejemplo, además de asociarse con la ideología tradicionalista, es decir, con el mantenimiento de los privilegios del antiguo régimen y de la Iglesia, se convierte en abanderado de la preservación del régimen foral en el País Vasco. Pero las fuerzas centrífugas no son sólo patrimonio del carlismo. Hacia finales de los sesenta, la facción federalista del partido demócrata adquiere tal poder que se consuma la escisión de los unitarios, que veían que el

5 "Hasta el más mínimo detalle es regulado por la Constitución de 1812, cuyo diseño de Estado unitario imponía los derechos de los españoles por encima de los históricos de cada reino. La igualdad de los ciudadanos reclamaba una burocracia centralizada, una fiscalidad común, un ejército nacional y un mercado liberado de la rémora de aduanas interiores. Sobre estos cimientos, la burguesía construirá, a través de los resortes de la administración, la nación española, cuya idea venía siendo perfilada desde el siglo anterior" (García de Cortázar y González Vesga 1993:431). partido hacía peligrar la unidad de España (García de Cortázar y González Vesga 1993:442). De hecho, la Constitución de 1873 (que no llegó a ver la luz) apostó por la organización del país según el modelo federal, dotando a los estados de "amplia autonomía política" (op.cit., p.439). Y fueron precisamente las fuerzas centrífugas del cantonalismo las que impidieron que este texto constitucional entrara en vigor. En este mismo contexto, no se puede dejar de mencionar la articulación política de los nacionalismos catalán, vasco y gallego.

A la inestabilidad política que afecta el clima intelectual de finales del diecinueve y principios del veinte, se suman polémicas idéológicas que desvelan los complejos e inseguridades que abruman a la intelectualidad española decimonónica, y bajo las cuales yace una profunda reflexión sobre el llamado 'probiema de España", es decir, sobre el estancamiento cuilturaí y eí atraso científico español con respecto a los vecinos europeos. La "polémica de la ciencia española' - en la que interviene un joven Menéndez Pelayo (1856-1912) y la polémica sobre la intolerancia religiosa y la Inquisición, protagonizada por Núñez de Arce (1834-1903), al pronunciar su discurso de ingreso en la Real Academia Española en 1876, y por Juan Valera (1824-1905), en su respuesta al anterior) ponen de manifiesto múltiples preocupaciones que aquejan a los intelectuales del diecinueve: dudas sobre la dignidad del pasado de España y desolación ante el "desierto intelectual" que caracterizaba su tiempo (Pérez Villanueva 1991:82-85).

La sensación de inseguridad nacional, motivada por la inestabilidad política y económica, por el peligro de desmembramiento, por la crisis de identidad cultural y por la apatía ciudadana, adquiere dimensiones insospechadas con la derrota militar sufrida por España frente a Estados Unidos y la pérdida de las últimas colonias del viejo imperio. El Desastre de 1898 hace que la intelectualidad española de fin de siglo tome conciencia de la necesidad de llevar a cabo la regeneración de España.

Ramón Menéndez Pidal fue una figura clave en este proceso de regeneración. Como afirma su más reciente biógrafo, Joaquín Pérez Villanueva, don Ramón se rebeló ya desde su juventud contra la visión pesimista que su admirado maestro, Menéndez Pelayo, tenía de la vida intelectual española de la época. Algo similar viene a expresar Malkiel, para quien la obra de Pidal, cuya magnitud y reconocimiento internacional están fuera de toda duda, se vio espoleada por la sorpresa y humillación que para él debió de haber supuesto el sentir general sobre el desierto intelectual de España, ${ }^{6}$ es decir, responde direc-

6 "[T]here must have been [...] something dazzling and, at the same time, profoundly
humiliating for a proud and ambitious young Spaniard, in his early twenties, to discover that, 
tamente al espíritu regeneracionista. El problema de la fragmentación de España lo preocupó también sobremanera. En escasísimas ocasiones intervino don Ramón directa y públicamente en cuestiones políticas; sin embargo, en el año 1931, decidió manifestar en la prensa su reacción frente a la concesión de un Estatuto de Autonomía a Cataluña y frente al decreto de bilingüismo. Se trata de su famoso artículo "Federarnos es algo parecido a divorciarnos", publicado en el diario El Sol el 26 de julio de 1931.

Pero el grito selvático que se ha lanzado en las regiones [...] tiene bastante de ruptura, cuando no se instaura para atar lo disgregado, sino para separar lo unido por siglos de historia. Federarnos es algo parecido a divorciarnos [...] Galicia, Vasconia,

Cataluña se puede decir que no vivieron un momento solas en la historia, perennemente unidas a un imperio toledano o leonés, a un imperio castellano, o a un reino aragonés. (Citado en Pérez Villanueva 1991:322)

Esta reacción frente a la supuesta fragmentación de España es indicativa del contexto ideológico en que vivió y trabajó y de los modelos interpretativos que a lo largo de su vida y obra desarrollaría. ${ }^{7}$

La adecuada contextualización de la producción intelectual de Menéndez Pidal nos exige ir más allá de las fronteras de España, pues a la España moderna iban llegando, más tarde o más temprano, con mayor o menor intensidad, los ecos de las corrientes científicas y filosóficas europeas. El clima filosófico y científico en Europa durante el siglo diecinueve y las primeras décadas del veinte fue igualmente propicio para un investigador astuto, receptivo y creativo como Menéndez Pidal. La historia intelectual de este período es producto de una atmósfera en la que se dan cita filosofías a la vez contradictorias y complementarias. Junto a la filosofía romántica, que daba al tacho con el racionalismo y la visión ordenada del universo del dieciocho, se desarrolla el positivismo científico, cuya metodología empírica y clasificatoria se proyecta de las

to secure dependable information on the sources of his own culture, he had to turn for help and guidance to foreign authorities, and that most of the braintrust was either concentrated in, or in the last analysis traceable to, a relatively small section of Europe which the 'Latin' intellectuals feared and admired, even trusted within certain limits, but only in rare instances sincerely liked" (Malkiel 1970:375).

${ }^{7}$ Al expresar su preocupación ante el peligro de fragmentación de la nación española, don Ramón se hacía eco de una polémica que venía de atrás. Véase lo significativo de las siguientes palabras que Juan Valera dedicaba en 1896 al intelectual regionalista gallego Manuel Murguía (1833-1923):

[Y]o no desdeño a los poetas y prosistas que hubo, hay y puede haber en dialecto gallego; que celebro el regionalismo filológico dentro de ciertos límites puramente providenciales; pero que deploro la exageración que puede ponernos en una lastimosa pendiente de desmoronamiento nacional o de cierto separatismo [...]. Cuando las grandes naciones y cuando las grandes razas decaen o se hunden, es cuando pierden el idioma común y salen hablando distintos idiomas. (Valera, Obras Completas II, p.910) ciencias naturales a las ciencias humanas. De modo igualmente paradójico, el historicismo decimonónico va arrojando luz sobre los sistemas sincrónicos y abriendo paso al nacimiento del estructuralismo. El individualismo, filosóficamente romántico y políticamente liberal, convive con la génesis del nacionalismo y de la consecuente indagación filosófica sobre conceptos tales como el espíritu nacional y la conciencia social.

\subsection{Contextualización del discurso lingüístico}

La figura intelectual de Menéndez Pidal ha sido objeto de numerosos estudios encomiásticos. En particular, el rigor científico de su trabajo filológico, que cumplio con la misión de elevar el prestigio de la ciencia filológica en España, llegó a generar lo que Malkiel ha denominado una incipiente leyenda blanca en torno a su persona. Lo mismo ocurrió con el componente teórico de su obra que, superado el positivismo inicial, lo convirtió en uno de los más audaces y creativos intérpretes de la historia de España. La última década ha visto la aparición de una nueva línea en la exégesis menendezpidaliana. Diversos autores han sentido la necesidad de contextualizar la obra de Ramón Menéndez Pical, situando en una tradición determinada y en un contexto socio-histórico específico tanto los fundamentos teóricos sobre los que se asienta como los modelos intelectuales que la inspiran. Trabajos de tipo general, tales como la Lingüistica íbero-románica de Diego Catalán o, más recientemente, la ya mencionada biografía de don Ramón realizada por Joaquín Pérez Villanueva, incorporan referencias a las circunstancias y el contexto político que de modo específico afectaron la producción pidaliana. No dejan, por ejemplo, de mencionar el clima intelectual de la Restauración, la crisis política de España o el precario estado de la ciencia española, que estimularon al por aquel entonces joven investigador.

El complejo de inferioridad intelectual que aquellas circunstancias generaron en la España de fin de siglo espoleó el orgullo del joven Pidal, que se impuso, como muchos de sus contemporáneos, la misión de devolver a España la dignidad perdida dotándola de una historia y un carácter elevados. Análisis más sistemáticos de la naturaleza ideológica de la filología menendezpidaliana aparecen en la breve biografía intelectual escrita por Steven Hess (1982:3031), que insiste en la orientación patriótica de la filología positivista de don Ramón, y en la historia de la filología española de José Portolés (1986:64-68), que insiste, si bien con brevedad, en situar a don Ramón en el contexto del regeneracionismo noventaiochista. En la actualidad, en la misma línea pero en un contexto crítico posmoderno, aparecen dos artículos que se proponen específicamente el análisis de la obra pidaliana como constructo cuyo objetivo es dotar de valor histórico y científico el concepto de nación española. Michael 
Gerli (en prensa), haciéndose eco de corrientes críticas que se proponen desvelar las fuerzas ideológicas del discurso cultural, afirma que la obra pidaliana está controlada por una idea central: la existencia de un carácter nacional español que se puede inducir por medio de la reconstrucción de la historia lingüística y literaria de España. Según Gerli, es así como la filología, en la obra pidaliana, se convierte en el instrumento científico que permite confirmar la existencia de una conciencia nacional y cultural. Catherine Brown (1995), desde una óptica similar, destaca en la obra menendezpidaliana un proceso de re-construcción de textos que, ante la pérdida y/o la ausencia de los originales, legitima y confirma una determinada visión de la identidad cultural española. No son éstos trabajos que persigan la desvalorización de la grandiosa obra de don Ramón. Muy al contrario. Lo que se proponen es precisamente tratar la obra del gran filólogo español con la seriedad y el rigor intelectual que se merece; como afirma C. Brown, 'leerla' y no sólo 'citarla', tratarla como 'texto' y no como 'supratexto' inamovible.

Un vistazo a los estudios exegéticos sobre la labor investigadora de Ramón Menéndez Pidal basta para observar que el componente linguístico ha quedado relegado a un segundo plano. No quiere esto decir que se le haya restado valor, sino que, al tratar de desvelar el esquema intelectual subyacente, se ha dado mayor prominencia al esfuerzo crítico literario y a la investigación historiográfica. Con frecuencia se reconoce la inconmensurable valía de, por ejemplo, el Manual u Orígenes pero sólo esporádica y brevemente son tratados en su dimensión de componentes integrales del discurso intelectual pidaliano. ${ }^{8}$ La linguística pidaliana merece atención especial por múltiples razones. Fue pionero de la lingüística moderna en España, siendo el primero en elaborar una gramática histórica de la lengua española según los cánones dominantes en Europa. A pesar de su riguroso conocimiento de los cánones, sus ideas lingüísticas tuvieron siempre la virtud de la flexibilidad, lo cual le permitió, por un lado, no quedar preso de los dogmas del historicismo lingüístico de corte alemán y poder contarse así entre los heterodoxos de la lingüística del cambio de siglo, y por otro, estimular a sus discípulos para que se adentraran en corrientes de investigación tales como la fonética, el estructuralismo o la estilística, que se distanciaban de su práctica. La originalidad de sus propuestas

8 Breves discusiones sobre el carácter ideológico de la lingüística pidaliana (en general referencias al significado de Orfgenes ) se encuentran en los estudios de Catalán (1974:62-64) donde lo ideológico no se discute sino que se insinúa indirectamente, Hess (1982:53-57 y 1996), Malkiel (1985:30-39) y Gerli (en prensa). En la misma línea crítica se pueden incluir observaciones acerca de la estrecha relación que Pidal establece entre lengua y cultura españolas (en los estudios citados y en Malkiel 1970), y en particular en ensayos de tipo divulgativo tales como "La lengua española" o La unidad del idioma (Hess 1982:62-65). teóricas lo hacen también merecedor de un lugar destacado entre los grandes lingüistas del siglo veinte. Por ejemplo, en el Manual, estudio de orientación claramente neogramática, incorporó datos procedentes del leonés anunciando tímidamente una de las grandes contribuciones de su Origenes, a saber, la integración de la concepción del cambio de los neogramáticos y de los dialectólogos. La necesidad de estudiar la linguística pidaliana se hace obvia de nuevo al reconocer el tremendo impacto que su trabajo tuvo en la formación de generación tras generación de filólogos españoles; no sólo los que él directamente formó en el Centro de Estudios Históricos sino también los que aprendieron el canon que él elaboró. No debemos olvidar quế el Manual (complementado por la Historia de la lengua de Rafael Lapesa) ha sido punto de partida (y en ocasiones, desafortunadamente, de destino) de todo estudioso de la historia de la lengua española. ${ }^{9}$ Y no han sido sólo los filólogos los que se han visto influidos por la sabiduría de don Ramón; cualquier lector español de mediana cultura ha podido acceder a muchos de sus escritos, publicados con carácter divulgativo y con el estilo característicamente accesible de don Ramón, en la colección Austral de Espasa-Calpe.

$\mathrm{Al}$ estudiar la obra pidaliana en conjunto, nos damos cuenta de que cada una de las disciplinas que la integran (estudios históricos, literarios y lingüísticos) cobra pleno sentido como parte del gran proyecto; sin embargo, es necesario prestar atención particular al desatendido componente lingüístico con fines analíticos. Advierte Portolés que "desvincular su preocupación teórica sobre la lengua de su aplicación en la indagación literaria hubiera escindido $a$ posteriori lo que unieron [los miembros de la escuela de Madrid] íntimamente, no por un desarrollo simultáneo, sino por la explicación de ambas como fruto de la misma sociedad o de igual individuo" (Portolés 1986:13). El objetivo aquí perseguido no es aislar la lingüística pidaliana como proyecto epistemológico independiente de los estudios literarios e históricos; lo que me propongo es profundizar en el cómo y el por qué de los procedimientos teóricos (principios y métodos) que se suponen exclusivamente lingüísticos, con el fin de entender el papel que desempeñan en el desarrollo de la filología española y la lingüística general, y de dilucidar en qué medida responden a una realidad socio-histórica e ideologica.

La escasa atención prestada al componente linguíístico de la obra pidaliana puede ser atribuida a la mitificación de que esta disciplina ha sido objeto. Los lingüistas, con frecuencia empeñados en definir su empresa como "el estudio

9 “[E]n 1904, sac6 a la luz un Manual elemental de gramática historica española que [...] todavía sigue editándose, y al cual han acudido a beber todas las generaciones de estudiosos de la lengua española" (Catalán 1974:23-24). 
científico del lenguaje", se imponen los requisitos de la objetividad y la neutralidad ideológica. La ilusión del estudio científico del lenguaje parecí́ hacerse realidad cuando las gramáticas prescriptivas dieron paso a las descriptivas y, más aún, cuando se consumó la objetivación del lenguaje (en último término asociado con organismos naturales por Schleicher), imprescindible para su estudio científico. La asunción en el siglo diecinueve de los principios que rigen el método positivista contribuyó grandemente a la consolidación del mito de la objetividad, y la lingüística histórica (la única científica en el siglo del historicismo) se articuló en torno al concepto de la ley fonética y a la reconstrucción paleográfica de documentos antiguos. Se impuso la idea de que existen hechos histórico-lingüísticos objetivos (leyes fonéticas o cambios lingüísticos) y textos históricos, y de que la misión del lingüista es formular la ley fonética correspondiente o reproducir el texto correspondiente, según el caso. La formulación o reconstrucción son verdaderas o falsas y su valor científico depende de su veracidad o falsedad. ${ }^{10}$

La caída en desuso de las aproximaciones positivistas al lenguaje y de la fe ciega en el valor intrínseco del dato histórico correctamente reproducido nos sugieren la necesidad de desentrañar las claves ideológicas de todo discurso lingüístico.

\section{Textos}

Tal como he venido proponiendo a lo largo de la sección anterior, la obra pidaliana contribuye a la construcción de una concepción de España, dándole, por medios científicos, una historia que la dignifique, generando para esa España unidad cultural, lingüística y, en consecuencia, política, e identificando los rasgos esenciales del carácter de su civilización. Aunque la obra lingüística de Menéndez Pidal se integra coherentemente en el conjunto de su producción intelectual, el tipo de modelos lingüísticos presentes en su obra no puede ser atribuido sólo a la circunstancia hispánica. El Manual por un lado, y Orígenes por otro revelan también la asimilación, asunción y superación de diversos modelos teóricos y concepciones del lenguaje nacidos fuera de España. ${ }^{11}$

10 A lo largo del siglo veinte se extiende la idea de que la dimensión cultural, estética y sociohistórica de la lingüística están condicionadas por prejuidios ideológicos. El monopolio de la objetividad linguíística pasa entonces a las escuelas formalistas (estructuralismo y generativismo); cf. Newmeyer (1986). La neutralidad ideologica que Newmeyer ha atribuido a formalismo ha sido desafiada por Joseph y Taylor (1990:2): "[A]ny claim that only a certain kind of linguistics is scientific presupposes a particular definition of science by the claimant - hence it is already an ideological proposition".

11 Ya se mencionó antes que precisamente una de las grandes virtudes de Pidal era su flexibilidad con respecto a la aplicabilidad de modelos teóricos, lo cual permitió no sólo su propia evolución sino la ampliación de las miras de sus discípulos.
Estos textos constituyen aportaciones fundamentales al desarrollo de la teoría lingüística en general y de la lingüística histórica española en particular, sin dejar por ello de ser producto de un contexto socio-histórico específico. El propósito de esta última sección es, precisamente, ofrecer una serie de comentarios sobre la emergencia de estos textos pidalianos.

De estos trabajos, el Manual es el que más fielmente responde a tendencias que tienen su origen fuera de España. Su publicación en 1904 significó la irrupción en España de un modo de estudiar el lenguaje que había estado fermentando en Europa desde la segunda década del siglo diecinueve: la lingüística comparativa e histórica. Sirvan, las siguientes citas, para mostrar la adopción explícita de estos modelos lingüísticos:

[L]a ciencia se tiene que valer, principalmente, de la restitución hipotética de las formas vulgares, por medio de la comparacion de los idiomas neolatinos. (Menéndez Pidal 1941:4; énfasis mío: JdV)

Confrontando el análisis de los sonidos modernos con las vagas iridicaciones de los gramáticos de tiempos pasados y con las mudanzas de la grafía a través de las diversas edades llegamos a conocer la evolución que interesa a la fonética. (Menéndez Pidal 1941:32; énfasis mío: JdV)

En concreto, son las tesis y modelos neogramáticos los que afectan de un modo más notable el contenido y organización del Manual. En el texto, tras la introducción, encontramos una sección (capítulos II y III) donde se presentan las leyes fonéticas (reglas o cambios lineales) que han dado forma a la lengua. Estos cambios lineales llevan al lector desde el latín al español estándar. Seguidamente, se encuentra una sección (capítulo IV) dedicada a las aparentes excepciones ("cambios fonéticos esporádicos"); la analogía es aquí el principio explicativo central. ${ }^{12}$ El libro se completa con una sección de morfología (capítulos V a VIII) donde, de nuevo, se echa mano con frecuencia de la analogía como principio explicativo. Tanto la estructuración de la gramática histórica como la prominencia de los conceptos de ley fonética y analogía son fiel reflejo de los principios metodológicos propuestos por Osthoff y Brugmann en el llamado manifiesto neogramático. ${ }^{13}$ Efectivamente, además de la organización general del libro, en las páginas del Manual, encontramos observaciones sobre la naturaleza del cambio linguístico y sobre el modo de estudi-

12 Nótese que, dada la presunción de la validez del principio de regularidad, las excepciones quedan fuera del ámbito de los mecanismos naturales de cambio y se justifican o bien afirmando que debe de haber una ley fonética no descubierta que explique la excepción o bien recurriendo a factores externos.

13 Me refiero, claro está, al Prefacio a la Morphologische Untersuchungen auf dem Gebiete der indogermanischen Sprachen, traducida al inglés en el libro de Lehmann $A$ reader in nineteenth-century historical linguistics (1967). 
arlo que mucho nos recuerdan a los principios neogramáticos. Nótense, por ejemplo, en la siguiente cita, los ecos del principio de regularidad, la referencia explícita al concepto de ley fonética o la mención del requisito de cientificidad:

Esa historia nos ha dado a conocer leyes o direcciones que obraron sobre todos 0 sobre la mayoría de los casos en que cada sonido se daba en igualdad de condiciones dentro de palabras [...] El descubrimiento de esas leyes fonéticas ha sentado el estudio del origen de las palabras sobre una base firme capaz de servir al trabajo cientifico (Menéndez Pidal 1941:175; énfasis mío: JdV). ${ }^{14}$

También en consonancia con los modelos linguísticos dominantes, la concepción menendezpidaliana de la historia de la lengua española es lineal, es decir, se trata de un proceso de evolución regido por leyes fonéticas propias que se extiende desde el período del latín hispánico hasta el del español moderno. Se da prioridad a las leyes fonéticas que conducen a la lengua estándar, y la supuesta homogeneidad de la lengua moderna se explica describiendo la historia de la lengua como un proceso de convergencia por medio del cual la heterogeneidad del pasado va quedando "absorbida" en el estándar homogéneo: 15

Este idioma hispano-romano, continuado en su natural evolución, es el mismo que aparece constituído ya como lengua literaria en el Poema del Cid, el mismo que perfecciono Alfonso el Sabio y, sustancialmente, el mismo que escribio Cervantes. (Menéndez Pidal 1941:8)

El castellano, por servir de instrumento a una literatura más importante que la de otras regiones de España, y sobre todo por haber absorbido en si otros dos romances principales hablados en la Península (el leonés y el navarro-aragonés), recibe más propiamente el nombre de lengua española. (Menéndez Pidal 1941:2; énfasis en cursiva mfo: JdV)

14 A pesar de la influencia neogramática evidente en el Manual y de observaciones como la anterior, sería injusto clasificar a Menéndez Pidal como un neogramático. La gran extensión de su carrera investigadora da pie para que se produzcan contradicciones y modificaciones de sus posicionamientos téricos. $\mathrm{Y}$ así lo demuestran las siguientes palabras, pronunciadas en una entrevista con Carmen Conde ya en los años sesenta:

La idea dominante en lingüistica era que las leyes fonéticas eran similares a las leyes naturales, leyes inevitables, sin excepciones, que se formaban y propagaban en un corto periodo de tiempo [...] Pero la lengua de aquellos documentos, tan libre, tan sincera en su expresión [...] daba una clara idea de la duración de un cambio fonético. (Conde 1969:36)

15 "In conventional historical description, three very prominent interrelated tendencies have been noticed. These are, first [...], a tendency to focus on patterns of change alone with little or no attention to stable patterns of language through time; second, a tendency to unidimensionality, that is, an inclination to think of the history of a language as the history of a single homogeneous variety and of sound-changes as proceeding in straight lines; and third [...], a tendency to impose theoretical and ideological orthodoxies on [...] data that might often be open to alernative kinds of interpretation. [...] for recent centuries models of language history are predominantly convergent" (Milroy 1992:49-50).
A pesar del predominio de la estructura, contenido y estilo del modelo neogramático en el Manual, se aprecian ya modos de concebir y estudiar la lengua y su historia que superan la rigidez doctrinal de la escuela alemana, insinuando una concepción más plural y compleja de la historia de la lengua. Qué duda cabe que en el Manual la historia de la lengua española es la historia del castellano, pero a ésta, insiste Pidal, hay que añadir las contribuciones léxicas de los pueblos que, a lo largo de la historia, entraron en contacto con 'el pueblo español', así como de los otros romances peninsulares y, por supuesto, del vasco. Es cierto que estas contribuciones quedan relegadas a un segundo plano, en consonancia con el modelo de convergencia adoṕtado por Menéndez Pidal, pero el hecho de que las mencione revela que su interés va más allá del carácter histórico-formal de la ley fonética para adentrarse en el terreno de lo histórico-cultural:

[E]n el estudio histórico-cultural del idioma los cultismos tienen una importancia principalísima, siendo lamentable que su conocimiento esté hoy tan atrasado. La ciencia habrá de aplicarse cada vez más intensamente a investigar la fecha, causas de introducción y destinos ulteriores de cada uno de estos prestamos, para que la historia lingüística adquiera su pleno valor. (Menéndez Pidal 1941:14-15)

En resumen, a nivel anecdótico, el Manual pudo surgir como elaboración de la gramática que acompañó a la edición del Poema del Cid o como simple respuesta a la necesidad sentida por don Ramón de crear un libro de texto para uso en sus clases de filología comparada del latín y el castellano. Sin embargo, enseguida se convirtió en una obra pionera y clave en la linguiística románica, al poner en práctica uno de los modelos teóricos dominantes (el neogramático) con detalles de originalidad que, a la larga, habrían de convertir a don Ramón en uno de los linguiistas más creativos del siglo veinte.

Recordemos, llegados a este punto, que la teoría de la emergencia (modelo de estudio histórico mencionado en los primeros párrafos de este artículo) nos invita a explorar, más allá de su valor científico, el horizonte socio-intelectual en que emerge una disciplina, una escuela o, más específicamente, un libro. Es más, nos sugiere que tras los textos aparentemente más asépticos, como podría ser el Manual, se esconde una tensión entre su valor científico y su valor ideológico.

El servicio ideológico que el modelo neogramático en particular y la linguiística histórica en general han venido prestando a la vida intelectual de los siglos diecinueve y veinte tiene su origen en la convergencia, durante el dieciocho, de la tradición lingüística racionalista y de la epistemología empirista. En el terreno específicamente lingǘrtico, el siglo dieciocho hereda el concepto de gramática universal y mantiene la conexión entre la lengua y la mente. En el 
terreno científico, la orientación epistemológica dominante, como resultado del éxito y prestigio de las ciencias naturales, entroniza la observación y la investigación empírica; y esto exige a los estudiosos del lenguaje tener en cuenta su dimensión observable. Es decir, los gramáticos del dieciocho tienen presentes a la vez la idea de la gramática universal, de la conexión entre lengua y mente y la innegable diversidad de las lenguas. La consecuencia filosofica de la convergencia de estas ideas, "según ha señalado Julia Kristeva (1989:172-173), fue la formulación de teorías sobre el origen del lenguaje. Si el pensamiento dominante impedía dar la espalda o relegar a un segundo plano el hecho de que todas las lenguas son diferentes, y si se sabe (o se supone) que bajo todas estas lenguas yace una misma gramática universal, parece lógico que se planteara que todas las lenguas han de proceder de una única lengua original.

La aparición de estas teorías sobre el origen del lenguaje sentó las bases para el desarrollo del comparatismo y de la lingüística histórica. Este paso se habría de dar, por un lado, cuando se acumularan datos suficientes para llevar a cabo la comparación y la reconstrucción de lenguas con el rigor metodológico que exigía la concepción dominante de la ciencia, y por otro, cuando las circunstancias culturales, filosóficas y sociales lo estimularan. La creación de la lingüística histórica fue más que una simple modificación de los modelos dominantes, más que la evolución de impulsos intradisciplinarios y el desarrollo de conceptos ya presentes en el período inmediatamente anterior. $\mathrm{Su}$ aparición y protagonismo responden también a estímulos ideológicos y epistemológicos que provenían, fundamentalmente, del historicismo positivista y del nacionalismo romántico.

Tal como señala Kristeva (1989:193-195), la aparición del historicismo, que ella sitúa en torno a la publicación de Outlines of a Philosophy of the History of Man (1784-1791) de Herder, fue producto de la reacción que generaron las importantes transformaciones que operaron sobre la sociedad europea del siglo dieciocho. Era necesario conciliar la idea racionalista de la existencia de un orden natural con la realidad de las transformaciones sociales. Fue así como se generó la necesidad de articular la idea de que el orden mismo (lejos de ser estático) genera evolución: "Historicism gave its reason for the rupture in order to find continuity after division" (Kristeva 1989:194). Con el historicismo, el conocimiento científico de un objeto pasa por la identificación y descripción del proceso por medio del cual ha llegado a ser lo que es. Por lo tanto, cualquier afirmación sustancial sobre un objeto digno de observación científica debe hacer referencia al "cómo ha llegado a ser". Los principios del historicismo conllevan la aplicación de un método inductivo que, por medio de la observación empírica, formule las leyes que rigen la evolución del objeto estu- diado. En consecuencia, el estudio científico de una lengua supone la descripción de las leyes que rigen su evolución.

El desarrollo de la lingüística histórica recibe también el impulso de la visión romántica del ser humano y de la sociedad. Para los románticos, el ser humano es individualista por instinto y social por necesidad. "La rebelión de los instintos solitarios contra los vínculos sociales" es, según Bertrand Russell, el motor de la ideología romántica. ${ }^{16}$ Ante la necesidad de vivir en sociedad, el ser humano siente el instinto de reafirmar su ego. ¿Cómo conciliar esta reafirmación individual con la vida en sociedad? Construyendo el concepto moderno de nación, es decir, proyectando las características del ego sobre el ente social. En otras palabras, la convivencia armónica con el otro es posible identificando el yo con la nación.

No es casual que coincidan en el tiempo el creciente protagonismo de la lingüística histórica y el desarrollo del concepto de -nación. Ya se mencionó antes que, a lo largo del siglo dieciocho, se mantuvo viva la idea de la existencia de una estrecha conexión entre la mente y el lenguaje. Esta conexión y sus implicaciones culturales fueron discutidas por ejemplo por Herder o Humboldt. Nos encontramos con que, por un lado, el lenguaje es una característica esencial de la mente humana, y por otro, la nación es una proyección de la sicología individual. La combinación de ambas ideas permite concluir que igual que el individuo expresa su pensamiento por medio de la lengua, la nación debe poder expresar el pensamiento colectivo también por medio de una lengua. La lingüística histórica, que, por supuesto, a nivel científico/práctico genera descripciones más adecuadas de la estructura de la lengua y del cambio lingüístico, se convierte también, a nivel ideológico, en un instrumento al servivio de la construcción del concepto de nación. Qué mejor manera de demostrar la existencia de una nación que describiendo su unidad lingüística; y qué mejor manera de demostrar esa unidad lingüística que dotándola de una historia usando el modelo epistemológico dominante, es decir, el historicismo positivista.

En este contexto lingüístico y filosófico, el Manual es un texto ejemplar. Desde el punto de vista teórico, sigue las pautas marcadas por la escuela dominante de linguiístia histórica: la escuela neogramática. Desde el punto de vista metodológico, se ajusta también a los cánones de la época, combinando el método comparativo con la base paleográfica que exige la filología positivista. En consonancia con la lingüística histórica decimonónica, el Manual define la

16 "Revolt of solitary instincts against social bonds is the key to the philosophy, the politics, and the sentiments, not only of what is commonly called the romantic movement, but of its progeny down to the present day" (Russell 1972:682). 
lengua española científicamente y la dota de una historia, tanto formal como cultural, contribuyendo así a forjar una unidad y una identidad histórico-cultural que son precisas para la constitución de la nación española de acuerdo con los modelos e intereses del liberalismo burgués decimonónico. ${ }^{17}$

\subsection{Los origenes de Orígenes}

En la misma línea se puede interpretar Orfigenes del español teniendo presente, claro está, que no es una simple elaboración del Manual, sino una verdadera obra maestra, un texto con carácter y objetivos propios que a todas luces supera en muchas dimensiones los plantemientos teóricos de la gramática histórica de 1904. Ya se explicó en párrafos anteriores que, a finales del siglo diecinueve, el concepto neogramático de ley fonética y el modelo de estudio histórico creado en torno a él dominaban el panorama lingüístico. Frente a la concepción unitaria de la lengua y a la regularidad de los procesos lingüísticos que se intuyen bajo el modelo neogramático, surgen a finales del diecinueve voces de oposición. ${ }^{18}$ Estas críticas se basan en la observación de la realidad lingüística (dialectal), que desvela la existencia de variación a todo nivel y en toda comunidad de habla, como resultado, al menos parcialmente, de la irregular aplicación de las leyes fonéticas. La conclusión obvia era que si las leyes fonéticas son irregulares, poco pueden tener de leyes. Los descubrimientos de la dialectología parecían asestar así un golpe mortal al modelo neogramático y, en consecuencia, a la concepción unitaria de la lengua que éste conllevaba.

Menéndez Pidal, en Or'genes del español, resuelve el dilema que dialectólogos planteaban a neogramáticos, al redefinir la ley fonética de modo tal que permite concebir su gradual propagación léxica, geográfica y social:

El espejismo [...] no se producirá si afirmamos la existencia de la ley fonética; se produciría si la negásemos, por no considerar el conjunto de una evolución secular sobre un territorio lingüístico de cierta unidad, y por limitarnos a la intensa contemplación de un solo instante del dialecto de una aldea. (Menéndez Pidal 1950:531)

En Orígenes, Menéndez Pidal reivindica la ley fonética y su poder unificador por medio de una brillante combinación de la perspectiva histórica y la pers-

\footnotetext{
17 La relación entre la emergencia de la historia de la lengua como disciplina académica y las preocupaciones sociales asociadas con el establecimiento del estado-nacion de corte liberal no es exclusiva de España. Un fenómeno muy similar se da, por ejemplo, en Inglaterra, según un reciente estudio de Tony Crowley (1996:147-188):

'the history of the language' belonged to the discourse of cultural nationalism which stressed continuity, that which is known, a sense of history, and gradual evolution. [...] 'the history of the language' and discourses like it were centripetal. (Crowley 1996:152)

18 De entre estas voces, Iordan (1967:41-60) destaca a Curtius, Ascoli, Schuchardt, Rousselot y Gauchat.
}

pectiva espacial. Es esta síntesis metodológica de las dimensiones diacrónica y diatópica lo que permite observar la variación y atisbar tras ella la lenta operación de la ley fonética. Me interesa subrayar el hecho de que el autor de Orígenes consiga integrar la heterogeneidad y la variación en un modelo de convergencia, homogeneizante, como es el que se construye en torno al concepto de ley fonética. Según Pidal, tras la variación opera 'una idéntica fuerza', 'una fuerte corriente', 'una tendencia general', una 'corriente general', 'una ley fonética'. ${ }^{19}$

La articulación del método histórico-dialectológico en Orígenes le permite también a Menéndez Pidal interpretar la lengua de los textós preliterarios como manifestación de la pugna entre diferentes normas linguísticas. Pidal parte del estudio de una serie de documentos de los siglos diez y once procedentes de $\mathrm{La}$ Rioja, León, Castilla y Aragón. Estos documentos, según el análisis de Orígenes, se caracterizan por la gran variación lingüística que presentan. El alto grado de variación es interpretado como resultado de la convivencia y competencia entre diversas normas, y prueba de que en la época preliteraria o "de orígenes" el idioma estaba aún "falto de una clara conciencia de sî" (Menéndez Pidal 1950:517), "falto de personalidad" (p.520), "falto de un alma" (p.529). En medio de esta crisis de identidad linguística, reflejo de una similar crisis de identidad cultural y de sentido histórico, Castilla fija la norma linguística antes que sus vecinos leoneses y aragoneses dando así muestra de su espíritu pionero y de su predestinación para desempeñar una misión rectora:

Castilla muestra un gusto acústico más certero, escogiendo desde muy temprano, y con más decidida iniciativa, las formas más eufónicas de estos sonidos vocálicos. (Menéndez Pidal 1950:486)

El dialecto castellano representa en todas esas características una nota diferencial frente a los demás đialectos de España, como una fuerza rebelde y discordante que surge en La Cantabria y regiones circunvecinas. (Menéndez Pidal 1950:487)

Esta concepción de Castilla como columna vertebral de España no aparece sólo en Orígenes (ni siquiera es exclusiva de Menéndez Pidal, pues bien conocida es la predilección por esta región de muchos de sus contemporáneos). A lo largo de su vida intelectual, don Ramón expresó frecuentemente su convicción de que a Castilla le había correspondido desempeñar el papel de

19 Debe quedar claro que la adopción por parte de Menéndez Pidal de un modelo de convergencia homogeneizante para la descripción histórica del español no implica una desatención o desinterés por la heterogeniedad, es decir, por la realidad dialectal española. No sólo estimulo don Ramón a sus discípulos para que hicieran progresar la dialectología, sino que él mismo fue pionero del trabajo de campo y, en particular, del estudio del leonés. Precisamente, una de las múltiples proezas intelectuales del gran filólogo español es el haber diseñado un modelo lingüístico que, partiendo de la heterogeneidad, genera unidad lingüística y cultural. 
fuerza centrípeta, integradora de la diversidad peninsular en una unidad linguística, cultural y política. Podría proponerse una larga lista de citas en las que don Ramón insiste en esta idea, pero valgan como ilustración las siguientes líneas procedentes de Los españoles en la historia:

[L]a misma imprevisora falta de interés, tan hispana, hacía que Castilla impulsase la acción más grandiosa de nuestra historia, sacrificando todas sus propias conveniencias a sus deberes hegemonicos. (Menéndez Pidal 1959:27)

[T]ambién la parte central, lo mismo que después Castilla, representa el núcleo cohesivo. (Menéndez Pidal 1959:117)

Aunque Menéndez Pidal expresó su rechazo de la identificación absoluta entre lengua y cultura ("alma del pueblo"), debemos recordar que sí creía firmemente que el estudio de la historia de una lengua nos puede ofrecer una síntesis de la historia del pueblo que la habla. ${ }^{20} \mathrm{De}$ este modo, la evidencia filológica del desarrollo temprano de una norma lingüística en Castilla nos ofrece unna visión de síntesis de su carácter emprendedor, rebelde, individualista y, en definitiva, de su misión rectora.

De nuevo debemos aceptar la invitación de la teoría de la emergencia, que nos incita a historificar esa contribución lingüística, es decir, a identificar los factores socio-históricos que hicieron posible y/o necesaria su aparición, además de resaltar su contribución al incremento del poder explicativo de la teoría lingüística. El valor analítico de la lingüística menendezpidaliana es abrumador, especialmente cuando nos percatamos de que no sólo diseñó modelos originales, sino que, visto desde la perspectiva actual, se anticipó a escuelas que, a finales del siglo veinte, están en la brecha de la investigación lingüística: el variacionismo y la hipótesis de la difusión léxica, entre otras. ${ }^{21}$ Ahora bien, estos avances no se dieron en el vacío, ni siquiera en un contexto exclusivamente lingüístico teórico. La teoría linguística elaborada por don Ramón emergió en un contexto socio-histórico específico, en un período en el que España está construyendo su identidad como estado-nación, en una fase en que esta construcción se ve amenazada, o al menos entorpecida, por fuerzas centrífugas que cuestionan la identidad cultural y política unitaria de España (tal

20 "Un idioma no es fundamentalmente, como tantas veces se dijo, la expresión del genio, índole o alma del pueblo que lo habla [...], es una síntesis de la historia del desenvolvimiento intelectual del pueblo que lo habla [...]. Expresa pues, sobre lodo, un diomestimiento civilización que afluyeron en el pueblo que lo habla" (Menedo, un idioma, las corrientes de Portolés 1986:55).

${ }^{21}$ Las conexiones entre la lingüística pidaliana y el variacionismo (los estudios sociolingüísticos inspirados por William Labov) han sido apuntadas por Paul Lloyd (1970). La hipótesis de la difusión léxica de los cambios se plantea en Wang (1977). No me consta que ningún difusionista reconozca a Menéndez Pidal entre sus precursores teóricos. como resumí en la sección segunda de este artículo). Es precisamente contra el telón de fondo de este panorama social e histórico que sugiero que se interprete la exploración filológica de antiguos documentos que llevó a Menéndez Pidal a ver confirmado el papel rector de Castilla en la historia de España, o su redefinición de la ley fonética como concepto integrador que nos permite vislumbrar unidad tras la variedad dilalectal. Quiero insistir una vez más en que el historificar un texto no significa negar su valor o cuestionar su veracidad, sino identificar la tensión entre ciencia e ideología que da lugar a su emergencia y notar la manifestación del contexto en el texto.

Como se mencionó en las primeras páginas de este trabajo, la España de los siglos diecinueve y veinte vive una crisis de identidad motivada en parte por el complejo de inferioridad intelectual frente a los vecinos europeos y en parte por el miedo a la fragmentación (o la imposibilidad de construir) de la nación española. En la España de la generación del-98 y en el contexto del regeneracionismo, la obra de Pidal supone un esfuerzo intelectual por generar unidad, por articular el concepto de España. En mi lectura de la obra del gran filólogo español, el Manual y Orígenes constituyen importantes pasos en el camino hacia la consecución de este objetivo. Creó textos dignos de la admiración de filólogos extranjeros, como prueban las reseñas recibidas, siguió fielmente los preceptos de la ciencia de su tiempo llegando incluso a superarlos, y dotó de historia a la lengua española, requisito indispensable para el reconocimiento científico de cualquier entidad; en este caso, de esa entidad nacional que es España.

\section{Dirección del autor:}

José del Valle

Department of Spanish \& Portuguese

Miami University

OXFORD, OH 45056, U. S. A.

e-mail: delvalj@miavx1.muohio.edu

\section{REFERENCIAS BIBLIOGRÁFICAS}

Brown, Catherine. 1995. "The Relics of Menéndez Pidal: Mourning and melancholia in Hispanomedieval studies". La corónica 24.15-41.

Carr, Edward Hallett. 1961. What is History? New York: Random House. Catalán, Diego. 1974. Lingǘística íbero-románica. Madrid: Gredos.

Conde, Carmen. 1969. Menéndez Pidal. Madrid: Unión Editorial.

Crowley, Tony. 1996. Language in History: Theories and texts. London \& New York: Routledge.

García de Cortázar, Fernando y José Manuel González Vesga. 1993. Breve historia de España. Madrid: Alianza Editorial. 
Gerli, Michael. En prensa. "Inventing the Spanish Middle Ages: Ramón Menéndez Pidal, Spanish cultural history, and ideology in philology". Studies in Honor of James $R$. Chatham ed. by Anthony Cárdenas. Madison: HSMS.

Hess, Steven. 1982. Ramón Menéndez Pidal. Boston: Twayne Publishers.

---1.-1996. "Castilian hegemony': Linguistics and politics in Origenes de español." La Corónica 24.114-122.

Joseph, John E. y Talbot J. Taylor, eds. 1990. Ideologies of Language. New York: Routledge.

Kristeva, Julia. 1989. Language: The unknown. Trad. por Anne M. Menke. New York: Columbia Univ. Press.

Lapesa, Rafael. 1981. Historia de la lengua española. 9a ed. Madrid: Gredos.

Laurendeau, Paul. 1990. "Theory of Emergence: Towards a historical-materialistic approach to the history of linguistics". Joseph y Taylor 1989.206-220.

Lehmann, Winfred P., ed. 1967. A Reader in Nineteenth-Century HistoricalComparative Linguistics. Bloomington \& London: Indiana Univ. Press.

Lloyd, Paul. 1970. "The Contribution of Menéndez Pidal to Linguistic Theory". Hispanic Review 38.14-21.

Malkiel, Yakov. 1970. "Era omme esencial ... ". Romance Philology 23.371411.

Menéndez Pidal, Ramón. 1918. "La lengua española”. Hispania 1.1-14.

1941[1904]. Manual de gramática histórica española. $6^{\mathrm{g}} \mathrm{ed}$. Madrid: Espasa-Calpe. - Español. 1944 . La unidad del idioma. Madrid: Instituto Nacional del Libro

-----. 1950[1926]. Orígenes del español: Estado lingüístico de la Península Ibérica hasta el siglo XI. $3^{\mathrm{a}} \mathrm{ed}$. Madrid: Espasa-Calpe.

1959 [1947]. Los españoles en la historia. Madrid: Espasa-Calpe.

1962[1921]. "Introducción al estudio de la linguíística vasca". En tor

no a la lengua vasca, 14-15. Buenos Aires: Espasa-Calpe.

1964[1908-1911]. Cantar de Mio Cid. Texto, gramática y vocabulario. 3 vols. $4^{\mathrm{a}}$ ed. Madrid: Espasa-Calpe.

Milroy, James. 1992.Linguistic Variation and Change. Oxford: Blackwell.

Newmeyer, Frederick J. 1986.The Politics of Linguistics. Chicago: Univ. of Chicago Press.

Pérez Villanueva, Joaquín. 1991. Ramón Menéndez Pidal. Madrid: EspasaCalpe.

Portolés, José. 1986. Medio siglo de filología española (1896-1952): Positivismo e idealismo. Madrid: Cátedra.

Russell, Bertrand. 1972. A History of Western Philosophy. New York: Simon \& Schuster.

Valera, Juan. 1958-1961. Obras Completas. Tomo II. Madrid: Aguilar.

Vilar, Pierre. 1985. Historia de España. 20 ed. Barcelona: Grijalbo.

Wang, William S-Y. 1977. The Lexicon in Phonological Change. The Hague: Mouton.

\section{SUMMARY}

The main tenet of this article is that Spanish philologist Ramón Menendez Pidal's (1869-1968) theoretical approach to the history of the language, as developed in his Manual de gramática histórica española (1904) and in Orígenes del español (1926), was a result not only of a highly original interpretation of the linguistic theories available to him and a need to improve their explanatory power, but also from an interplay between this theory and the ideological context from which it emerged. This ideological context, which I maintain is critical for the understanding of the full implications of Menéndez Pidal's linguistic approach, has been assumed by traditional historiography to be outside the scope of linguistics. It is claimed here that the Spanish philologist's scholarly accomplishments, justly praised by his disciples and hispanists in general, did not occur in a social vacuum, but were instead well entrenched in a specific intellectual, social, and historical context. Menéndez.Pidal lived and worked in a period in which Spain, like other 19th-century liberal'democracies, was building its identity as a nation-state. In this period, the construction of the Spanish nation was threatened by centrifugal forces (e.g., the articulation of Basque, Catalan, and Galician nationalisms) that challenged Spain's unitary political and cultural identity. It is precisely against the backdrop of this socio-political landscape that Menéndez Pidal's use of the neogrammarian model of convergence in the Manual, his scrupulous philological examination of old documents in Origenes is interpreted - which, for him, offered proof of Castile's destiny as the leading force in the history of Spain, including his integrative reworking of the phonetic law converting it into a means by which to perceive the unity underlying dialectal variation.

\section{RÉSUMÉ}

La thèse principale de cet article est que l'approche theorique de l'histoire du langage dévelopée par le philologue espagnol Ramón Menéndez-Pilal (1869-1968) dans son Manual [elemental] de gramática histórica española (première édition publiée en 1904) et dans Orígenes del español (première édition publiée en 1926), ne reflète pas seulement une interprétation très originale des théories linguistiques disponibles et un besoin d'améliorer leur pouvoir explicatif. Le développement de sa théorie doit être placé dans le contexte idéologique où elle est apparue. Selon l'historiographie traditionelle, ce contexte idéologique, central à la compréhension des conséquences de l'approche linguistique de Menéndez-Pilal, se trouve en dehors du champ de la linguistique. Cet article démontre que les travaux linguistiques et scientifiques du philologue espagnol, loués à juste titre par ses disciples et par les hispanistes en général, n'existaient pas dans un vide social, mais se trouvaient au contraire bien implantés dans un contexte intellectuel, social et historique particulier. Menéndez-Pidal a vécu et travaillé à l'époque où l'Espagne, comme 